\title{
Risk Analysis of Cargos Damages for Aquatic Products of Refrigerated Containers: Shipping Operators' Perspective in Taiwan
}

\author{
Wen-Jui Tseng ${ }^{1},{ }^{*}$ Ji-Feng Ding ${ }^{2}$, Chien-Chang Chou ${ }^{1}$, Fu-Ting $\mathrm{Hsu}^{3}$, Yu-Meng Wang ${ }^{4}$, Ya-Ning Liu ${ }^{5}$, Nai-Wen \\ Chang ${ }^{4}$, Yi-Wen $\mathrm{Wu}^{6}$ \\ ${ }^{1}$ National Kaohsiung Marine University, Taiwan \\ ${ }^{2}$ Chang Jung Christian University Tainan, Taiwan \\ ${ }^{3}$ Fubon Insurance Co., Ltd., Taiwan \\ ${ }^{4}$ Kaohsiung Harbor Bureau, Taiwan \\ ${ }^{5}$ Yang Ming Marine Transport Corp. Taiwan \\ ${ }^{6}$ China Sea Shipping Agency Ltd, Taiwan \\ *jfding@mail.cjcu.edu.tw
}

\begin{abstract}
As the development of refrigerated container, transportation of aquatic products is growing rapidly in recent years. It is very important to avoid cargos damages for aquatic products of refrigerated containers, while the shipping operators are running this scope of business. Hence, the risk issue of adopting various improvement strategies would be important for the container shipping operators. In the light of this, the main purpose of this paper is to analyze the risks of cargos damages for aquatic products of refrigerated containers based on the container shipping operators' perspective in Taiwan. We use four risk assessment procedures - risk identification, risk analysis and evaluation, risk strategies, and risk treatment - as the research method in this paper. The risk factors are generated from literature review and experts interviewing. Then, three dimensions with nineteen risk factors are preliminary identified. We used these risk factors to proceed with the empirical study via questionnaires. Three points of empirical results are presented. At first, the top factor of perceived risk as well as of risk severity is 'container data setting errors.' Secondly, the top factor of risk frequency is 'lack of the goods' pre-cooling themselves.' Thirdly, three risk factors are classified into the low-risk area, whereas sixteen risk factors are placed on the medium-risk area. There is no risk factor fix on the high-risk area. Furthermore, three risk strategies - risk prevention, risk reduction, and risk transfer - are suggested to adopt by different risk factors.
\end{abstract}

Keywords: Risk analysis, aquatic product, container-shipping operator.

\section{Introduction}

The improving of living standard and the rapidly increasing demand toward fresh ingredients around the world has led the gradual rise of refrigerated container transport in Taiwan. Practically, frozen cargos are divided into three types in accordance with the temperature of cool, cold $\left(0{ }^{\circ} \mathrm{C}\right.$ and above), and frozen $(0$ ${ }^{\circ} \mathrm{C}$ and below), respectively. The cargos of frozen goods are mainly frozen aquatic products and frozen poultry meat. Frozen aquatic products can be further divided into low fat aquatic products (between -18 $\left.{ }^{\circ} \mathrm{C} \sim-23{ }^{\circ} \mathrm{C}\right)$, high-fat fish $\left(-29^{\circ} \mathrm{C}\right.$ or less), and some red meat and fish (low temperature of $-6{ }^{\circ} \mathrm{C}$ ). According to the 2010 statistics data provided by Council of Agriculture (COA) in Taiwan, Taiwan's aquatic products export worth about 1.22 billion U.S. dollars, accounting for $35.6 \%$ of the all-agricultural exports that ranked the highest. The main types of export aquatic products are fish (mainly tuna, eel, skipjack and tilapia of more than $70 \%$ of the total), molluscs/mollusks, crustaceans, and other aquatic products with major exporting countries of Japan, Thailand and United States; followed by livestock products of export value of approximately 12.0 billion U.S. dollars with accounting for about $35 \%$ of the total. Therefore, Taiwan is the country with very high aquaculture technology development and with high quality of seafood, which has very strong competitiveness on the export.

Due to the large transportation capacity of the refrigerated ship, the refrigerated container has the advantages of fast, convenient, easy maintenance etc., leading the extensive use of refrigerated containers. Secondly, transport freight of refrigerated containers charge 3-5 times more than dry freight containers for the average (Fang, 1992). The profits are greater than dry freight containers even although the market of refrigerated containers is not as large as dry freight containers. Thus, there are many container carriers 
entered the market of refrigerated containers. Although the value of refrigerated contain ers is normally higher than dry freight containers, the claim amount of refrigerated containers when there is damage to the cargos is usually larger than the dry freight ones. Therefore, the issue of aquatic product on transport risk management of refrigerated containers seems very important.

After searching the relevant literature, the themes of risk assessment (e.g. Blackhurst et al., 2008; Giovanna and Lorenzo, 2011; KarimiAzari et al., 2011; Lavasani et al., 2011; Lichtenberg, 2010; Misra et al., 2007; Ni et al., 2010; Shang and Tseng, 2010; Sheehan, 2010; Sunil and ManMohan, 2004; Tsai and Su, 2005; Tseng et al., 2011; Tummala and Schoenherr, 2011; Yang, 2010) are very important. However, the risk management issue of aquatic products of refrigerated container shipping transport was found very lack in this study. Therefore, as the development of refrigerated container transportation of aquatic products is growing rapidly in recent years. It is very important to avoid cargos damages for aquatic products of refrigerated containers, while the shipping operators are running this scope of business. Hence, the risk issue of adopting various improvement strategies would be important for the container shipping operators. In short, this study aims at evaluating the cargos damages on aquatic risk analysis for container operators who are running refrigerated containers. The following section presents the materials and methods. Consequently, an empirical survey is studied. Finally, some conclusions are made in the last section.

\section{Literature Review and Methodology}

Risk assessment is a management process which consists four procedures (Shang and Tseng, 2010; Tsai and Su, 2005; Tseng and Li, 2011; Tseng et al., 2011; Yang, 2010), including risk identification, risk analysis and evaluation, risk strategies, and risk treatment. We use the four risk assessment procedures as the research method in this paper.

Risk identification: Risk identification is the first procedure of risk assessment. Risks could not be managed without prior identification before occurrence (Billington, 1999). In other words, only a comprehensive understanding to the various risks of the corporation may predict the possible risks involved and further choose the effective approach for risk processing. The main purpose of risk identification lies on the identification of all predictable risks. In this study, risk identification is mainly done by literature review and interviews with experts to find the risk factors of cargos damages occurrence for shipping operators running refrigerated containers for aquatic products. The risk identification proposed in this paper is generated from literature review (Chou, 1997; Chow, 1988; Fang, 1992; Shao, 2002; Shao et al., 2005; Wang, 1997; Xiao, 2004) and experts interviewing. Hence, three dimensions and nineteen preliminarily risk factors for cargos damages are suggested; and their codes are shown in parentheses.

- Operational risk. This dimension includes seven risk factors, that is, 'the risk of container loss temperature due to the unplug right after the container entered the container terminal $\left(A_{1}\right)$,' 'the risk of container data setting errors (such as temperature, ventilation) $\left(A_{2}\right)$,' 'the risk of damage caused by insecure packaging or binding on board $\left(A_{3}\right)$,' 'data setting errors caused by production errors of shipping documents or loading documents $\left(A_{4}\right)$,' 'the damage risk of goods inside the container due to the container damaged caused by improper operation of equipments $\left(A_{5}\right)$,' 'the damage risk of goods inside the container due to improper stacking in the storage area that caused container damages $\left(A_{6}\right)$,' and 'the damage risk of goods caused by delayed goods delivery due to a shipment delay $\left(A_{7}\right)$,' respectively.

- Hardware risk. This dimension includes six risk factors, that is, 'the risk of improper pre-cooling containers (the pre-cool not reach the set temperature) $\left(B_{1}\right)$,' 'the temperature risk caused by generator failure in the towing process $\left(B_{2}\right)$,' 'the risk of unfound abnormal operation of equipment or cabinet damage due to the undone freezer inspection in advance $\left(B_{3}\right)$,' 'the cargo damage risk caused by container temperature loss due to the failure of wharf power supply system $\left(B_{4}\right)$,' 'the risk of normal temperature maintenance due to defrost system failure resulting in excessive frost $\left(B_{5}\right)$,' and 'the cargo damage risk due to power supply system failure on board resulting in temperature loss $\left(B_{6}\right)$,' respectively.

- Consignors risk. This dimension includes six risk factors, that is, 'the risk of the lack of the goods' pre-cooling themselves $\left(C_{1}\right)$,' 'the risk of goods temperature loss due to the excessive container loading time $\left(C_{2}\right)$,' 'the temperature loss risk of goods near the container door due to the excessive 
stack above the standard, resulting in short cycle in the container $\left(C_{3}\right)$,' 'the risk of the owners' wrong conception of the temperature setting toward their own products $\left(C_{4}\right)$,' 'the consignee return risk due to quarantine failure caused by unfamiliarity of custom declaration requirements (quarantine) $\left(C_{5}\right)$,' and 'the cargo damage risk caused by the improper (wrong) packaging $\left(C_{6}\right)$,' respectively.

Risk analysis and evaluation: About risk analysis and evaluation, a number of studies (Manuele, 2010; Peltier, 2004; Tseng et al., 2011) have applied the 'risk matrix model (RMM)' to assess placement of risk levels. A RMM can help risk managers to develop highly efficient risk management strategies through different zones of risk levels in accordance with various risk factors; hence, in attempt to lower loss occurrence rates and to reduce financial impacts for corporations. The Australian/New Zealand Standard (i.e., AS/NZS 4360: 2004) is a common risk management standard model. The AS/NZS 4360 model is used in the second procedure of the risk assessment in this paper. The AS/NZS 4360 proposes the concept of risk assessment level matrix, dividing the major factors of risk analysis into two dimensions, i.e., risk frequency and risk severity.

- Risk frequency. The term refers to a specific risk within a certain period. The number of times for a specific risk incident to occur in a risk unit (probability) is divided into five levels (i.e., 1-5), in the order of: (5) almost certain, (4) likely, (3) moderate, (2) rare, and (1) unlikely, respectively.

- Risk severity. The term refers to the severity of loss caused from a specific risk occurring within a certain period of time, which is also divided into five levels (i.e., 1-5), in the order of: (5) catastrophe, (4) major, (3) moderate, (2) minor, and (1) insignificant, respectively.

The AS/NZS 4360 assesses the probability of risk occurrence and the loss severity carried through the RMM (as shown in Figure 1), helping organizations to establish risk management and strategies, and effective allocating resources with respect to the various risks (Shang and Tseng, 2010; Yang, 2010).

Figure 1: The Risk Matrix

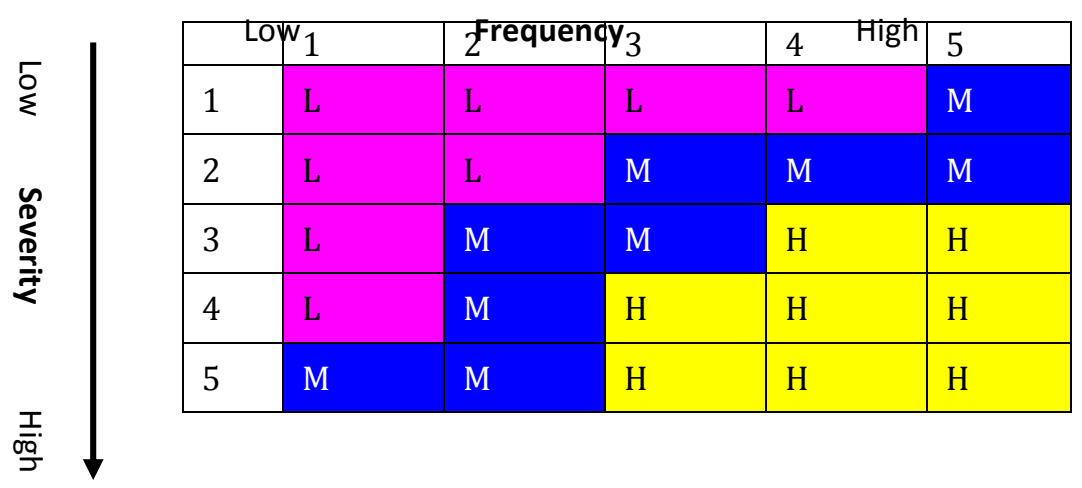

After the estimation completion of the risk frequency and risk severity, this study defines risk value as the value after the multiplatinum of risk frequency and risk severity. Finally, risk value was divided into three risk areas in this study according to Shang and Tseng's (2010) advices including:

- The risk belongs to low-risk area when the risk value is between grades 1-4;

- The risk belongs to medium-risk area when the risk value is between grades 5-14;

- The risk belongs to high-risk area when the risk value is between grades 15-25.

Risk strategies: Risk management strategies are often divided into categories of risk control and risk financing (Smeltzer and Siferd, 1998; Sunil and ManMohan, 2004; Tseng et al., 2011; Uher and Toakley, 1999). The former refers to the strategies or measures made towards lowering risk occurrence rate and loss frequency. The purpose aims to prevent and reduce loss. Common risk control strategies or measures include risk avoidance, risk transfer, loss prevention, and loss reduction. The later refers to financial planning, including finance funding as rapid restoration to situation prior to risk occurrences. Commons risks financing strategies or measures include risk retention, and insurance. 
Empirical Study Questionnaire and Data Collection: The data of three dimensions and nineteen risk factors were collected via questionnaires, which were divided into three parts. Part I is related to the basic data; meanwhile the Part II measures the perceived risks of nineteen factors, which were based on a Likert 5-point scale, ranging from ' 1 ' for 'strongly disagreed' to ' 5 ' for 'strongly agreed.' The Part III is to measure risk frequency and severity by Likert 5 -point scale. The frequency of risk occurrence is ' 5 ' for very often (once a month), ' 4 ' for often (once every one to six months), ' 3 ' for sometimes (once a year), ' 2 ' for rare (once every one to three years), and ' 1 ' for very rare (once every five years or over), respectively. The severity of the risk occurrence is ' 5 ' for very severe (loss of more than a million), ' 4 ' for severe (loss of 0.5 to 1 million), ' 3 ' for moderate (loss of 0.3 to 0.5 million), ' 2 ' for not serious (loss of 0.1 to 0.3 million), and ' 1 ' for slight (loss under 0.1 million or less), respectively.

The questionnaire was filled in by the related participants of various maritime communities in Taiwan, including container carriers, ocean freight forwarders, and container terminal operators. In addition, the surveys were completed through e-mails, phone calls, and in-person interviews conducted by the authors. 186 valid samples were collected from the 200 questionnaires, which represents $86 \%$ of the total questionnaires. The reliability (Hair et al, 2010) of the article applies Cronbach's $\alpha$ to measure the consistency of all factors covered in each dimension. If the coefficient of Cronbach is, $\alpha$ falls higher than 0.7 , it is a high value of reliability. After conducing reliability analysis, the average value for each dimension can reach over 0.7 , and it is therefore a high reliability value. Because the questionnaire of this paper introduces questionnaires with literature or practical verifications collected by related experts, and hence the paper contains reasonable content validity (Hair et al, 2010).

The basic statistics information in the questionnaire survey is summed up and shown as follows: (1) most participants are above 31 years old (85\%); (2) most are employed above 11 years (65\%); (3) the position of staffs and first-line managers are accounted for 67\%; (4) most companies are founded above 21 years (50\%); and (5) most are employed in shipping carriers (85\%).

\section{Results and Discussion}

The results of the mean, the standard deviation (S.D.), and the rank of the perceived risk, risk frequency, and risk severity are shown in Table 1 . The key points in Table 1 can be summarized as follows. The means of top three factors of perceived risks are 'container data setting errors $\left(A_{2}\right)$,' 'the temperature risk caused by generator failure in the towing process $\left(B_{2}\right)$,' and 'container loss temperature due to the un-plug right after the container entered the container terminal $\left(A_{1}\right)$,' respectively. Contrarily, the means of latter three ones are 'the damage risk of goods caused by delayed goods delivery due to a shipment delay $\left(A_{7}\right)$,' 'goods temperature loss due to the excessive container loading time $\left(C_{2}\right)$,' and 'the damage risk of goods inside the container due to improper stacking in the storage area that caused container damages $\left(A_{6}\right)$,' respectively.

The means of top three factors of risk frequency are 'the lack of the goods' pre-cooling themselves $\left(C_{1}\right)$,' 'the damage risk of goods caused by delayed goods delivery due to a shipment delay $\left(A_{7}\right)$,' and 'the temperature loss risk of goods near the container door due to the excessive stack above the standard, resulting in short cycle in the container $\left(C_{3}\right)$,' respectively. Contrarily, the means of latter three ones are 'damage caused by insecure packaging or binding on board $\left(A_{3}\right)$,' 'the damage risk of goods inside the container due to improper stacking in the storage area that caused container damages $\left(A_{6}\right)$,' and 'the cargo damage risk caused by container temperature loss due to the failure of wharf power supply system $\left(B_{4}\right)$,' respectively.

The means of top three factors of risk severity are 'container data setting errors $\left(A_{2}\right)$,' 'the cargo damage risk due to power supply system failure on board resulting in temperature loss $\left(B_{6}\right)$,' and 'the cargo damage risk caused by container temperature loss due to the failure of wharf power supply system $\left(B_{4}\right)$,' respectively. Contrarily, the means of latter three ones are 'goods temperature loss due to the excessive container loading time $\left(C_{2}\right)$,' 'the temperature risk caused by generator failure in the towing process $\left(B_{2}\right)$,' and 'improper pre-cooling containers $\left(B_{1}\right)$,' respectively.

According to the risk frequency and risk severity in Table 1, the risk matrix for aquatic products can be drawn as shown in Figure 2. In order to facilitate the identification of relative importance of each risk 
item, the risk levels are divided into three areas according to Shang and Tseng's advices (2010). They are low-risk area, medium-risk area, and high-risk area, respectively. Finally, the position of each factor item can be shown in the Figure 2. In summary, we can obtain that (i) three risk factors, i.e. $A_{3}, A_{6}$, and $B_{4}$, are classified into the low-risk area; (ii) sixteen risk factors, i.e. $A_{1}, A_{2}, A_{4}, A_{5}, A_{7}, B_{1}-B_{3}, B_{5}, B_{6}$, and $C_{1}-C_{6}$, are placed on the medium-risk area; and (iii) there is no risk factor fix on the high-risk area.

Table 1

\begin{tabular}{|c|c|c|c|c|c|c|c|c|c|c|}
\hline \multirow{2}{*}{\multicolumn{2}{|c|}{ Risk factors }} & \multicolumn{3}{|c|}{ Perceived risk } & \multicolumn{3}{|c|}{ Risk frequency } & \multicolumn{3}{|c|}{ Risk severity } \\
\hline & & \multirow{2}{*}{$\begin{array}{l}\text { Mean } \\
4.08\end{array}$} & \multirow{2}{*}{$\begin{array}{l}\text { S.D. } \\
0.97 \\
5\end{array}$} & \multirow{2}{*}{$\begin{array}{l}\begin{array}{l}\text { Ran } \\
\mathbf{k}\end{array} \\
3\end{array}$} & \multirow{2}{*}{$\begin{array}{l}\begin{array}{l}\text { Mea } \\
\mathbf{n}\end{array} \\
1.87 \\
5\end{array}$} & \multirow{2}{*}{$\begin{array}{l}\text { S.D. } \\
0.88 \\
5\end{array}$} & \multirow{2}{*}{$\begin{array}{l}\text { Rank } \\
13\end{array}$} & \multirow{2}{*}{$\begin{array}{l}\text { Mean } \\
3.813\end{array}$} & \multirow{2}{*}{$\begin{array}{l}\text { S.D. } \\
1.276\end{array}$} & \multirow[t]{2}{*}{ Rank } \\
\hline $\begin{array}{l}A \\
1\end{array}$ & $\begin{array}{l}\text { The risk of container loss temperature due } \\
\text { to the unplug right after the container } \\
\text { entered the container terminal }\end{array}$ & & & & & & & & & \\
\hline $\begin{array}{l}A \\
2\end{array}$ & $\begin{array}{l}\text { The risk of container data setting errors } \\
\text { (such as temperature, ventilation) }\end{array}$ & 4.34 & $\begin{array}{l}0.67 \\
5\end{array}$ & 1 & $\begin{array}{l}2.31 \\
2\end{array}$ & $\begin{array}{l}0.94 \\
6\end{array}$ & 8 & 4.250 & 0.856 & 1 \\
\hline $\begin{array}{l}A \\
3\end{array}$ & $\begin{array}{l}\text { The risk of damage caused by insecure } \\
\text { packaging or binding on board }\end{array}$ & 4.0 & $\begin{array}{l}0.83 \\
3\end{array}$ & 10 & $\begin{array}{l}1.37 \\
5\end{array}$ & $\begin{array}{l}0.61 \\
9\end{array}$ & 17 & 3.875 & 1.360 & 6 \\
\hline $\begin{array}{l}A \\
4\end{array}$ & $\begin{array}{l}\text { Data setting errors caused by production } \\
\text { errors of shipping documents or loading } \\
\text { documents }\end{array}$ & 4.04 & 0.90 & 8 & 2.0 & $\begin{array}{l}0.73 \\
0\end{array}$ & 11 & 4.063 & 1.124 & 4 \\
\hline $\begin{array}{l}A \\
5\end{array}$ & $\begin{array}{l}\text { The damage risk of goods inside the } \\
\text { container due to the container damaged } \\
\text { caused by improper operation of } \\
\text { equipments }\end{array}$ & 4.05 & $\begin{array}{l}0.80 \\
5\end{array}$ & 6 & $\begin{array}{l}1.56 \\
3\end{array}$ & $\begin{array}{l}0.81 \\
3\end{array}$ & 16 & 3.750 & 1.238 & 10 \\
\hline $\begin{array}{l}A \\
6\end{array}$ & $\begin{array}{l}\text { The damage risk of goods inside the } \\
\text { container due to improper stacking in the } \\
\text { storage area that caused container } \\
\text { damages }\end{array}$ & 3.55 & $\begin{array}{l}1.32 \\
7\end{array}$ & 19 & $\begin{array}{l}1.37 \\
5\end{array}$ & 0.5 & 17 & 3.0 & 1.155 & 15 \\
\hline $\begin{array}{l}A \\
7\end{array}$ & $\begin{array}{l}\text { The damage risk of goods caused by } \\
\text { delayed goods delivery due to a shipment } \\
\text { delay }\end{array}$ & 3.63 & $\begin{array}{l}1.04 \\
7\end{array}$ & 17 & 3.0 & $\begin{array}{l}1.26 \\
5\end{array}$ & 2 & 3.0 & 1.095 & 15 \\
\hline $\begin{array}{l}B \\
1\end{array}$ & $\begin{array}{l}\text { The risk of improper pre-cooling } \\
\text { containers (the pre-cool not reach the set } \\
\text { temperature) }\end{array}$ & 3.95 & $\begin{array}{l}0.95 \\
1\end{array}$ & 11 & $\begin{array}{l}1.75 \\
0\end{array}$ & $\begin{array}{l}0.93 \\
1\end{array}$ & 14 & 2.688 & 1.448 & 19 \\
\hline $\begin{array}{l}B \\
2\end{array}$ & $\begin{array}{l}\text { The temperature risk caused by generator } \\
\text { failure in the towing process }\end{array}$ & 4.26 & $\begin{array}{l}0.60 \\
9\end{array}$ & 2 & $\begin{array}{l}2.43 \\
8\end{array}$ & $\begin{array}{l}1.15 \\
3\end{array}$ & 6 & 2.938 & 1.289 & 18 \\
\hline $\begin{array}{l}B \\
3\end{array}$ & $\begin{array}{l}\text { The risk of unfound abnormal operation of } \\
\text { equipment or cabinet damage due to the } \\
\text { undone freezer inspection in advance }\end{array}$ & 4.05 & $\begin{array}{l}0.93 \\
4\end{array}$ & 6 & 2.0 & $\begin{array}{l}1.09 \\
0\end{array}$ & 11 & 4.063 & 0.929 & 4 \\
\hline $\begin{array}{l}B \\
4\end{array}$ & $\begin{array}{l}\text { The cargo damage risk caused by container } \\
\text { temperature loss due to the failure of } \\
\text { wharf power supply system }\end{array}$ & 3.90 & $\begin{array}{l}1.07 \\
4\end{array}$ & 12 & $\begin{array}{l}1.37 \\
5\end{array}$ & $\begin{array}{l}0.61 \\
9\end{array}$ & 17 & 4.125 & 1.147 & 3 \\
\hline $\begin{array}{l}B \\
5\end{array}$ & $\begin{array}{l}\text { The risk of normal temperature } \\
\text { maintenance due to defrost system failure } \\
\text { resulting in excessive frost }\end{array}$ & 4.02 & $\begin{array}{l}1.32 \\
7\end{array}$ & 9 & $\begin{array}{l}2.37 \\
5\end{array}$ & $\begin{array}{l}0.88 \\
5\end{array}$ & 7 & 3.688 & 0.873 & 11 \\
\hline $\begin{array}{l}B \\
6\end{array}$ & $\begin{array}{l}\text { The cargo damage risk due to power } \\
\text { supply system failure on board resulting in } \\
\text { temperature loss }\end{array}$ & 4.07 & $\begin{array}{l}0.82 \\
6\end{array}$ & 5 & $\begin{array}{l}1.62 \\
5\end{array}$ & 0.50 & 15 & 4.188 & 0.981 & 2 \\
\hline $\begin{array}{l}C \\
1\end{array}$ & $\begin{array}{l}\text { The risk of the lack of the goods' } \\
\text { pre-cooling themselves }\end{array}$ & 3.84 & $\begin{array}{l}0.85 \\
9\end{array}$ & 14 & $\begin{array}{l}3.31 \\
3\end{array}$ & $\begin{array}{l}1.07 \\
8\end{array}$ & 1 & 3.313 & 1.195 & 12 \\
\hline $\begin{array}{l}C \\
2\end{array}$ & $\begin{array}{l}\text { The risk of goods temperature loss due to } \\
\text { the excessive container loading time } \\
\text { The temperature loss risk of goods near }\end{array}$ & 3.62 & $\begin{array}{l}0.83 \\
9\end{array}$ & 18 & $\begin{array}{l}2.87 \\
5\end{array}$ & $\begin{array}{l}0.95 \\
7\end{array}$ & 5 & 3.0 & 1.033 & 15 \\
\hline $\begin{array}{l}C \\
3\end{array}$ & $\begin{array}{l}\text { the container door due to the excessive } \\
\text { stack above the standard, resulting in short } \\
\text { cycle in the container }\end{array}$ & 4.08 & $\begin{array}{l}0.59 \\
3\end{array}$ & 3 & $\begin{array}{l}2.93 \\
8\end{array}$ & $\begin{array}{l}0.85 \\
4\end{array}$ & 3 & 3.063 & 1.124 & 14 \\
\hline $\begin{array}{l}C \\
4\end{array}$ & $\begin{array}{l}\text { The risk of the owners' wrong conception } \\
\text { of the temperature setting toward their } \\
\text { own products }\end{array}$ & 3.88 & $\begin{array}{l}0.89 \\
2\end{array}$ & 13 & $\begin{array}{l}2.06 \\
3\end{array}$ & $\begin{array}{l}1.06 \\
3\end{array}$ & 10 & 3.813 & 1.167 & 7 \\
\hline $\begin{array}{l}C \\
5\end{array}$ & $\begin{array}{l}\text { The consignee return risk due to } \\
\text { quarantine failure caused by unfamiliarity } \\
\text { of custom declaration requirements } \\
\text { (quarantine) }\end{array}$ & 3.78 & $\begin{array}{l}0.93 \\
9\end{array}$ & 16 & $\begin{array}{l}2.12 \\
5\end{array}$ & $\begin{array}{l}0.88 \\
5\end{array}$ & 9 & 3.813 & 0.911 & 7 \\
\hline $\begin{array}{l}C \\
6\end{array}$ & $\begin{array}{l}\text { The cargo damage risk caused by the } \\
\text { improper (wrong) packaging }\end{array}$ & 3.80 & $\begin{array}{l}0.74 \\
8\end{array}$ & 15 & $\begin{array}{l}2.87 \\
5\end{array}$ & $\begin{array}{l}1.31 \\
0\end{array}$ & 4 & 3.313 & 1.138 & 12 \\
\hline
\end{tabular}


Figure 2: The Risk Matrix of Aquatic Products of Refrigerated Containers

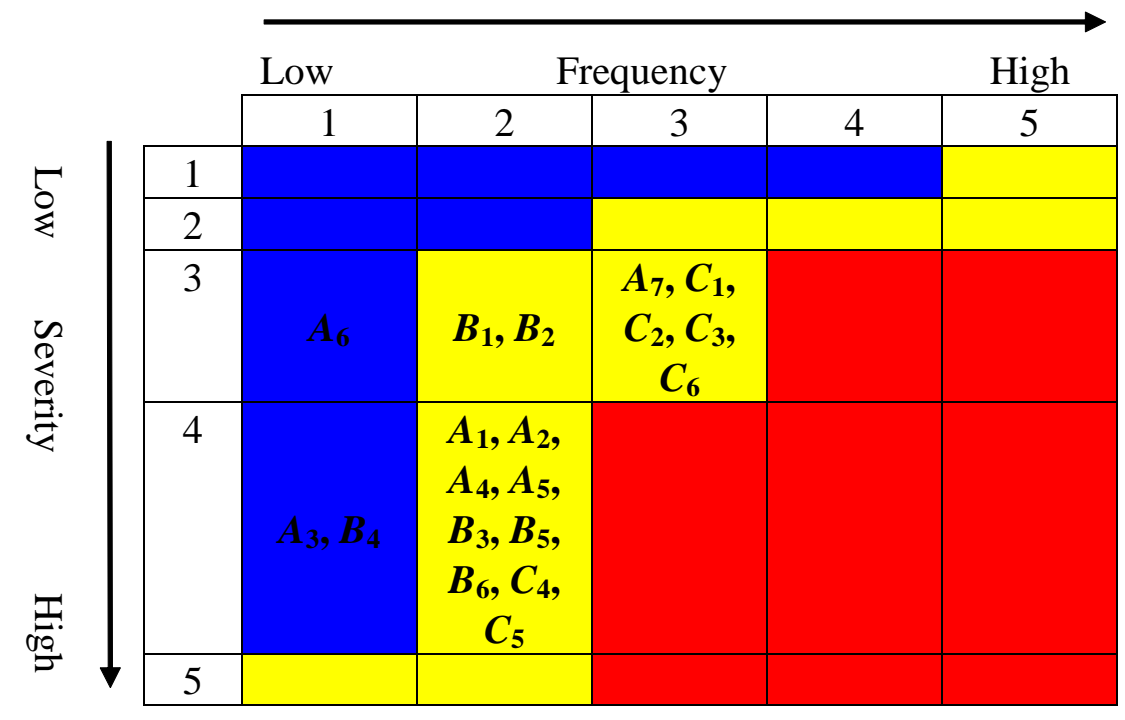

While considering the actual situations with occurrences in the process that container shipping operators delivering frozen aquatic products at different risk attribute, we interviewed and discussed with related experts of these fields and scholars in Taiwan. Then, shipping operators obtain the risk strategies for various risk factors. We conclude that when the risk severity of loss is high; however, the risk retention is not realistic in the practice. On the other hand, when the high probability of loss is occurred in a specific incident, the insurance is a costly expense. Some techniques of risk solutions are necessary for risk strategies; some key points are shown as follows: At first, those risk strategies characterized by high frequency and low severity are most appropriately dealt with risk prevention to lower the potential probability. Secondly, these ones with low frequency and high severity are most properly used risk reduction to minimize the aggregate amount of losses that must be borne. Meanwhile, those ones we can cope with risk transfer to shift risks to the third party, e.g. insurance contract or disclaimer agreement. In short, the principle of risk strategies are divided into three categories of risk prevention, risk reduction, and risk transfer, as described below:

- Risk prevention. The risk strategy to reduce the possibility of loss, which is the measure before the occurrence of an accident. For example, the strengthening of on-the-job training, the thorough implementation of SOP, and so on.

- Risk reduction. The risk strategy to reduce the impact after the loss occurrence, which can be applied before, or after the accident occurrence. For example, the maintenance of refrigerated container equipment, the intensification of packaging, and so forth.

- Risk transfer. The risk strategies of risk transferring to others through insurance contracts or otherwise before the accident. For example, risk transfer through insurance contracts, the addition of disclaimer agreement in transport contracts, etc.

In summary, we used the above-mentioned principle of risk strategies and discussed with the related experts and scholars in Taiwan, the principles of risk management strategies can be adopted by different risk factors, as shown in Table 2. It is suggested that these risk strategies can be applied to the container shipping operators when they are running the frozen container cargoes of aquatic products in the shipments of container transport process in Taiwan. Nevertheless, these strategies of transport risk could be widely different among various industries. 


\begin{tabular}{ccc}
\multicolumn{3}{c}{ Risk strategies } \\
\hline Risk & Risk & Risk \\
prevention & reduction & transfer
\end{tabular}

The risk of container loss temperature due to the

$A_{1}$ unplug right after the container entered the container terminal

$A_{2}$ The risk of container data setting errors (such as temperature, ventilation)

$A_{3} \quad$ The risk of damage caused by insecure packaging or binding on board

$A_{4}$ Data setting errors caused by production errors of shipping documents or loading documents The damage risk of goods inside the container due

$A_{5}$ to the container damaged caused by improper operation of equipments

The damage risk of goods inside the container due

$A_{6}$ to improper stacking in the storage area that caused container damages

$A_{7}$ The damage risk of goods caused by delayed goods delivery due to a shipment delay

$B_{1}$ The risk of improper pre-cooling containers (the pre-cool not reach the set temperature)

$B_{2}$ The temperature risk caused by generator failure in the towing process

The risk of unfound abnormal operation of

$B_{3}$ equipment or cabinet damage due to the undone freezer inspection in advance

The cargo damage risk caused by container

$B_{4}$ temperature loss due to the failure of wharf power supply system

The risk of normal temperature maintenance due

$B_{5}$ to defrost system failure resulting in excessive frost

The cargo damage risk due to power supply

$B_{6}$ system failure on board resulting in temperature loss

$C_{1}$ The risk of the lack of the goods' pre-cooling themselves

$C_{2}$ The risk of goods temperature loss due to the excessive container loading time

The temperature loss risk of goods near the

$C_{3}$ container door due to the excessive stack above

$C_{3}$ the standard, resulting in short cycle in the

container

$C_{4} \quad$ The risk of the owners' wrong conception of the

4 temperature setting toward their own products

The consignee return risk due to quarantine

$C_{5}$ failure caused by unfamiliarity of custom declaration requirements (quarantine)

$C_{6}$ The cargo damage risk caused by the improper (wrong) packaging

$\sqrt{ } \quad \sqrt{ }$

$\sqrt{ }$

$\sqrt{ } \sqrt{ }$

$\sqrt{ }$

$\sqrt{ } \sqrt{ }$

$\sqrt{ } \sqrt{ }$

$\sqrt{ }$

$\sqrt{2}$

$\sqrt{ }$

$\sqrt{ }$
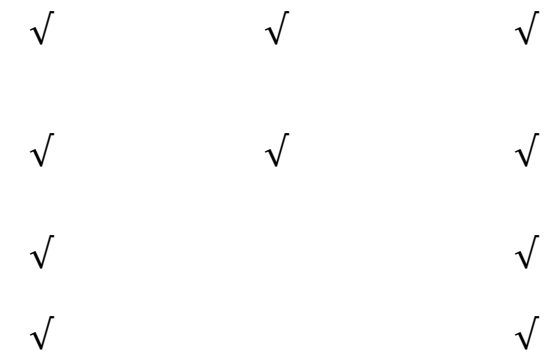

$\sqrt{ } \sqrt{ }$
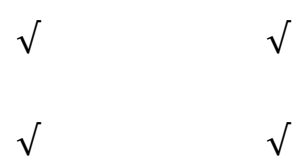

$\sqrt{ } \sqrt{ }$




\section{Conclusion}

As the development of refrigerated container, transportation of aquatic products is growing rapidly in recent years. It is very important to avoid cargos damages for aquatic products of refrigerated containers, while the shipping operators are running this scope of business. Hence, the main purpose of this paper is to evaluate the risks of cargos damages for aquatic products of refrigerated containers based on the shipping operators' perspective in Taiwan. At first, the four risk procedures of risk assessment - risk identification, risk analysis and evaluation, risk strategies, and risk treatment - are described in this paper. About risk identification, three dimensions with nineteen preliminary risk factors are generated from literature and experts interviews. About risk analysis and evaluation, a RMM using an AS/NZS 4360 model has been constructed through risk frequency and risk severity, in order to place risk degree. Finally, an empirical survey is studied. The results show that:

- The top factor of perceived risk is 'container data setting errors, such as temperature and ventilation.' Contrarily, the last one is 'the damage risk of goods inside the container due to improper stacking in the storage area that caused container damages.'

- The top factor of risk frequency is 'the lack of the goods' pre-cooling themselves.' Contrarily, the last three ones are 'the damage caused by insecure packaging or binding on board,' 'the damage risk of goods inside the container due to improper stacking in the storage area that caused container damages,' and 'the cargo damage risk caused by container temperature loss due to the failure of wharf power supply system,' respectively.

- The top factor of risk severity is 'container data setting errors.' Contrarily, the last one is 'improper pre-cooling containers.'

- In summary, three risk factors are classified into the low-risk area, whereas sixteen risk factors are placed on the medium-risk area. There is no risk factor fix on the high-risk area

In addition, three recommended principles of risk management strategies - risk prevention, risk reduction, and risk transfer - according to the risk area of various risk factors' occurrence were given in this study. However, the evaluation of risk management costs and benefits was not done in this study. It is suggested for follow-up studies of risk cost-benefit analysis to focus on the risk reduction with effective risk management methods in a reasonable price. Moreover, this paper focused on the refrigerated container transportation of aquatic products, we think our paper can be contributed to the transport risks of the frozen aquatic products. If the readers are interesting in the similar cases in the future, they can apply the same procedures on the risk management.

\section{References}

Billington, C. J. (1999). Managing Risk in Port, Managing Risk in Shipping, UK: P\&I CLUB.

Blackhurst, J. V., Scheibe, K. P. \& Johnson, D. J. (2008). Supplier Risk Assessment and Monitoring for the Automotive Industry. International Journal of Physical Distribution and Logistics Management, 38(2), 143-165.

Chou, B. Y. (1997). The Study on Cargo Damage of Reefer Containers, Master Thesis, Taiwan: National Taiwan Ocean University.

Chow, C. J. (1988). Effect of Freezing and Thawing on the Discoloration of Tuna Meat. Nippon Suisan Gakk, $54(4), 639-648$.

Fang, X. X. (1992). Study on the Transportation of Refrigerated Cargo at Sea, Master Thesis, Taiwan: National Taiwan Ocean University.

Giovanna, L. N. \& Lorenzo, A. (2011). Risk Assessment and Profit Sharing in Business Networks. International Journal of Production Economics, 131(1), 234-241.

Hair, J. F., Black, W. C., Babin, B. J. \& Anderson, R. E. (2010). Multivariate Data Analysis: A Global Perspective ( $7^{\text {th }}$ ed.). New York: Prentice Hall Company.

KarimiAzari, A., Mousavi, N., Mousavi, S. F. \& Hosseini, S. (2011). Risk Assessment Model Selection in Construction Industry. Expert Systems with Applications, 38(8), 9105-9111.

Lavasani, S. M. M., Yang, Z., Finlay, J. \& Wang, J. (2011). Fuzzy Risk Assessment of Oil and Gas Offshore Wells. Process Safety and Environmental Protection, 89(5), 277-294.

Lichtenberg, E. (2010). Economics of Health Risk Assessment. Annual Review of Resource Economics, 2(1), 53-75. 
Manuele, F. A. (2010). Acceptable Risk. Professional Safety, 55(5), 30-38.

Misra, S. C., Kumar, V. \& Kumar, U. (2007). A Strategic Modeling Technique for Information Security Risk Assessment. Information Management and Computer Security, 15(1), 64-77.

Ni, H., Chen, A. \& Chen, N. (2010). Some Extensions on Risk Matrix Approach. Safety Science, 48(10), 1269-1278.

Peltier, T. R. (2004). Risk Analysis and Risk Management. Information Systems Security, 13(4), 44-56.

Shang, K. C. \& Tseng, W. J. (2010). A Risk Analysis of Stevedoring Operations in Seaport Container Terminals. Journal of Marine Science and Technology, 18(2), 201-210.

Shao, T. Y. (2002). Reefer Container Routing Design of Fishery Products. Journal of the Fisheries Society of Taiwan, 29(2), 129-137.

Shao, T. Y., Lee, H. S. \& Pan, C. L. (2005). The Study of Temperature Management of Reefer Container in Low Temperature Logistics System. Maritime Quarterly, 14(4), 1-14.

Sheehan, N. T. (2010). A Risk-based Approach to Strategy Execution. Journal of Business Strategy, 31(5), 25-37.

Smeltzer, L. R. \& Siferd, S. P. (1998). Proactive Supply Management: The Management of Risk. International Journal of Purchasing and Materials Management, 34(1), 38-45.

Standards Australia and Standards New Zealand (AS/NZS). (2004). AS/NZS 4360: 2004, Risk Management. Sydney \& Standards New Zealand.

Sunil, C. \& ManMohan, S. S. (2004). Managing Risk to Avoid Supply Chain Breakdown. MIT Sloan Management Review, 46(1), 53-61.

Tsai, M. C. \& Su, C. H. (2005). Political Risk Assessment of Five East Asian Ports - The Viewpoints of Global Carriers. Marine Policy, 29(4), 291-298.

Tseng, W. J. \& Li, M. H. (2011). The Risk Analysis of Fishing Vessel Accidents. Journal of Underwriting, 19, 105-117.

Tseng, W. J., Ding, J. F., Chou, C. C., Wang, J. L., Chung, P. C., Tseng, T. L., Syue, H. S. \& Lin, M. T. (2011). Transport Risks Analysis of Temperature-controlled Cargoes for Airfreight Forwarders in Taiwan: Case Study of the Orchids. African Journal of Agricultural Research, 6(27), 5992-5998.

Tummala, R. \& Schoenherr, T. (2011). Assessing and Managing Risks Using the Supply Chain Risk Management Process (SCRMP). Supply Chain Management, 16(6), 474-483.

Uher, T. E. \& Toakley, A. R. (1999). Risk Management in the Conceptual Phase of a Project. International Journal of Project Management, 17(3), 161-169.

Wang, C. H. (1997). Study on the Transportation of Reefer Container in Temperature Management, Master Thesis, Taiwan: National Taiwan Ocean University.

Website of Council of Agriculture (COA) in Taiwan. (2011). http://www.coa.gov.tw/show_index.php [15 December 2011].

Xiao, B. R. (2004). An Evaluation of Market Segmentation in Reefer Services, Master Thesis, Taiwan: National Cheng Kung University.

Yang, Y. C. (2010). Impact of the Container Security Initiative on Taiwan's Shipping Industry. Maritime Policy Management, 37(7), 699-722. 